\title{
Bird Diets in Urban Environments: The Case of the Asian Glossy Starling, Aplonis panayensis
}

\author{
Nursyafiqah Shazali, J. Mohd-Azlan, and Andrew Alek Tuen
}

\begin{abstract}
The Asian Glossy Starling, Aplonis panayensis, is one of the most abundant birds in Kuching City, occupying nooks and cavities of buildings and soiling the walls and floors with their droppings. To determine why they are so abundant, we focused on their dietary habits in a study conducted in Dewan Suarah area of Kuching in 2013. A total of 51 fecal samples were collected from the floor of Dewan Suarah and examined for dietary fragments. The results showed the diet comprises insects as well as plant parts. The insects are solely from the Order Hymenoptera (70 individuals), whereas the plant parts comprised figs ( $86 \%$ ), Vitex sp. $(2 \%)$ and unidentified plant materials (12\%). The Hymenopteran identified in fecal samples belong to the family Agaonidae (45 individuals), Formicidae (18 individuals), and Ormyridae (7 individuals). There is a significant difference in frequency occurrence of insects and fruits in the diet of starlings. From the fecal analysis, the insects in the diet of the starlings are mainly from the figs they have eaten. The diet of the bird is discussed in relation to the availability of food items in the surrounding areas.
\end{abstract}

\section{Introduction}

Pro-development government policies and rising human population has transformed the landscape of many Southeast Asian countries, including Malaysia, through deforestation and urbanization (Flint 1994). Urban population in Malaysia increased from $34 \%$ in 1980 to $71 \%$ in 2010 (Department of Statistics Malaysia 2012). This rapidly changing landscape has caused many animal species to lose their original

\footnotetext{
N. Shazali • J. Mohd-Azlan

Department of Zoology, Faculty of Resource Science and Technology,

Universiti Malaysia Sarawak, 94300 Kota Samarahan, Sarawak, Malaysia

A.A. Tuen $(\bowtie)$

Institute of Biodiversity and Environmental Conservation,

Universiti Malaysia Sarawak, 94300 Kota Samarahan, Sarawak, Malaysia

e-mail: aatuen@ibec.unimas.my
} 